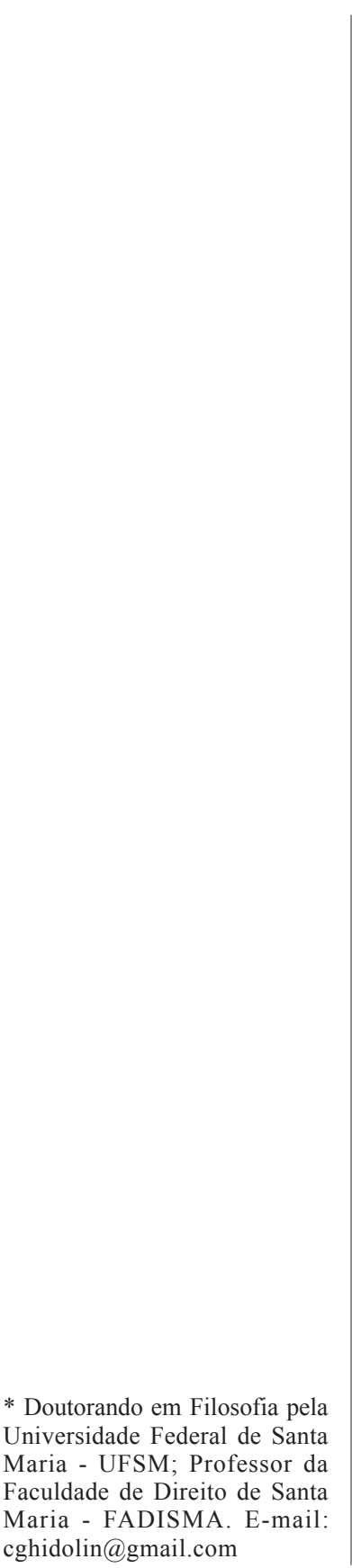

\section{Classificação em princípios e regras na deliberação jurídica e moral}

\section{Classification in PRINCIPLES AND RULeS ON RESOLUTIONS LEGAL AND MORAL}

\section{Clodoveo Ghidolin *}

Resumo: O objetivo desse trabalho é apresentar a classificação dos princípios e regras no sistema jurídico, analisar suas funções, seus prováveis conflitos e os métodos de solução dos mesmos. Em seguida, comparar esses mesmos conceitos com a deliberação moral. Por fim, identificar as semelhanças e diferenças entre os sistemas jurídico e moral.

Palavras-chave: Princípios; Regras; Moral.

Abstract: The aim of this paper is to present the classification of principles and rules in the legal system, to analyze their functions, their probable conflicts and methods of solution to them. Then, compare these same ideas in moral deliberation. Finally, identify similarities and differences between legal and moral systems.

Keywords: Principles; Rules; Morals. 


\section{INTRODUÇÃO}

Teria sido o desenvolvimento do Direito influenciado pela Moral? A resposta a esta pergunta é, obviamente, sim, o que não implica, de modo algum, que uma resposta também afirmativa não possa ser dada à pergunta inversa. Foi o desenvolvimento da Moral influenciado pelo Direito? (HART, 1987, p.31).

A epígrafe acima, do Jusfilósofo Herbert Hart, sugere que a relação entre o Direito e a Moral é histórica, mútua e permite inúmeras comparações; algumas teorias sustentam a tese da identidade entre Direito e Moral (sociedades primitivas), outras uma mera conexão (Jusnaturalistas e PósPositivistas) e outras, ainda, uma completa separação (Positivistas). Além disso, há os que sustentam que a Moral (predominante) possa exercer influência sobre o Direito bem como o Direito sobre a Moral (predominante) (DIMOULIS, 2003, p.104). Mas o propósito, desse artigo, é analisar apenas princípios e regras do Direito, comparar esses mesmos conceitos presentes na Moral, e identificar semelhanças e diferenças.

Um sistema jurídico pode ser analisado sob várias perspectivas, mas uma em especial representa a base do Direito contemporâneo e a chave para a solução de vários problemas envolvendo a Dogmática Jurídica, a saber, a distinção entre princípios e regras. Essa classificação não é nova, porém nossa atenção inicia com os escritos de Ronald Dworkin, mais especificamente no segundo capítulo da obra "Levando os Direitos a Sério". Dworkin defende uma tese contrária ao positivismo de Hart (Direito como a união de regras primárias e secundárias) por não representar a complexidade das novas estruturas do sistema normativo. O Direito deve ser composto não somente por regras, mas também por princípios que servirão, entre outras funções, para auxiliar o raciocínio jurídico diante de casos difíceis e proporcionar soluções para aqueles em que as regras não dão conta.

Esse mesmo conjunto de pares (princípios e regras) pode ser analisado sob a perspectiva da Moral, não apenas para estabelecer uma simples classificação, mas para demonstrar como os princípios morais estão envolvidos na justificação e estabelecimento das regras morais. Eles são considerados como dispositivos invariáveis que servem para criar novas regras morais, mudar as antigas, oferecer soluções mais adequadas, 
funcionando como método para preencher lacunas e resolver eventuais antinomias entre regras. Por fim, pretendemos identificar as semelhanças e diferenças entre o Direito e a Moral.

\section{PRINCÍPIOS E REGRAS NO DIREITO}

Um ordenamento jurídico é caracterizado como sistema, ordem axiológica ou teleologia de princípios gerais. Um conjunto de normas que deve respeitar três características fundamentais, a saber, unidade, coerência e completude (BOBBIO, 1999). A unidade representa a fonte geradora de todas as regras (através da chamada "Norma Fundamental," descrita por Kelsen, aquela que confere validade a todas as demais normas do sistema) apoiada nos princípios eleitos pelo Estado. Além disso, as regras estão estruturadas em hierarquia e no topo estão os valores. Toda regra de conduta deve ser criada a partir dos princípios desta "pirâmide" jurídica. Já a completude é a exigência de pelo menos uma norma para solucionar cada caso, ou seja, o ordenamento não deve possuir lacunas (espaço jurídico vazio). Por fim, a coerência representa a ausência de antinomia, incompatibilidade entre normas para o mesmo caso. Nesse ponto é preciso distinguir "norma jurídica" de "regras, dispositivos, princípios". Nas palavras de Eros R. Grau:

[...] norma é a interpretação do texto normativo, ou seja, do dispositivo de lei, da regra ou do princípio. O que em verdade se interpreta são os textos normativos; da interpretação dos textos resultam as normas. A interpretação é, portanto, a atividade que se presta a transformar textos disposições, preceitos, enunciados - em normas (2006, p.27).

Assim, o Direito deve ser composto tanto por regras, que estabelecem o "dever ser", quanto por princípios que servirão, entre outras funções, para auxiliar o raciocínio jurídico diante de casos de difícil solução. Ainda segundo Dworkin, a diferença entre regras e princípios pode ser entendida da seguinte maneira:

Os dois conjuntos de padrões apontam para decisões particulares acerca da obrigação jurídica em circunstâncias específicas, mas distinguem-se quanto à natureza da orientação que oferecem. As regras são aplicáveis à maneira do tudo-ou-nada. Dados os fatos que uma regra estipula, então ou a regra é 
válida, e neste caso a resposta que ela fornece deve ser aceita, ou não é válida, e neste caso em nada contribui para a decisão [...]. Mas não é assim que funcionam os princípios no direito. Mesmo aqueles que mais se assemelham as regras não apresentam conseqüências jurídicas que se seguem automaticamente quando as condições são dadas [...]. Os princípios possuem uma dimensão que as regras não tem - a dimensão do peso ou importância. Quando os princípios se entrecruzam, aquele que vai resolver o conflito tem de levar em conta a força relativa de cada um [...]. As regras não têm essa dimensão (DWORKIN, 2002, p.39-43).

Portanto, as regras formam o direito de uma determinada comunidade a fim de estabelecer o que "deve" ou "não deve" ser feito pelo indivíduo (obrigações, autorizações, permissões ou proibições). Elas são chamadas de densas (DIMOULIS, 2003, p.77), pois são normas de "tudo ou nada" (são respeitadas ou não) e não deixam margem para dúvidas, ou seja, elas são taxativas. Para exemplificar esse caso, Carrió (1998, p.217) utiliza a regra que estabelece a velocidade máxima de uma rodovia em $80 \mathrm{~km} / \mathrm{h}$ : ou se está dentro do limite ou não se está - tertium non datur.

Por outro lado, a caracterização de princípio, exposta acima, não parece ser exaustiva, pois esse conceito pode sofrer também do problema da "textura aberta" da linguagem (STRUCHINER, 2002), isto é, existem outras formas para expressar o significado de princípios. Segundo Carrió são, pelo menos, sete possibilidades:

[...] I) parte o ingrediente importante de algo, propiedad fundamental, núcleo básico, característica central; II) regla, guía, orientación o indicación generales; III) fuente generadora, causa u origen; IV) finalidad, objetivo, propósito o meta; V) premisa, inalterable punto de partida para el razonamiento, axioma, verdad teórica postulada como evidente, esencia, propiedad definitoria; VI) regla práctica de contenido evidente, verdad ética incuestionable; VII) máxima, aforismo, proverbio, pieza de sabiduría práctica que nos viene del pasado y que trae consigo el valor de la experiencia acumulada y el prestigio de la tradición. (1998, p.209).

Podemos encontrar outras cinco descrições de princípios (ATIENZA; MANERO, 2005, p.25): a) Normas em sentido geral que regulam casos cujas propriedades relevantes são muito gerais; b) Normas presentes no ordenamento e que são vagas; c) Normas programáticas ou diretrizes que obrigam os órgãos competentes a atingir certos fins determinados; d) Normas 
que expressam valores superiores do ordenamento jurídico; e) Normas dirigidas aos órgãos aplicadores do direito no processo de decisão.

Ademais, princípio jurídico é uma norma muito geral ou aquela que regula um conteúdo abrangente. Desempenha uma função positiva com relação às decisões judiciais, pois fornece conteúdo para auxiliar na obtenção de uma solução mais adequada, equilibrada, razoável ou ponderada. Ao mesmo tempo, cumpre uma função negativa no sentido de que exclui valores contrapostos e das normas opostas que repousam sobre esses valores. Nas palavras de Celso B. de Mello:

Princípio - já averbamos alhures - é, por definição, mandamento nuclear de um sistema, verdadeiro alicerce dele, disposição fundamental que se irradia sobre diferentes normas compondo-lhes o espírito e servindo de critério para sua exata compreensão e inteligência exatamente por definir a lógica e a racionalidade do sistema normativo, no que lhe confere a tônica e lhe dá sentido harmônico (apud, GRAU, 2006, p.148).

As normas programáticas ou diretrizes determinam fins ou buscam a realização de certas metas estabelecidas no próprio ordenamento, a exemplo dos princípios positivados em nossa Constituição Federal. Segundo Atienza e Manero:

Los principios son normas que ordenan que se realice algo en la mayor medida posible, en relación con las posibilidades jurídicas y fácticas. Los principios son, por consiguiente, mandatos de optimización que se caracterizan porque pueden ser cumplidos en diversos grados y porque la medida ordenada de su cumplimiento no sólo depende de las posibilidades fácticas, sino también de las posibilidades jurídicas (2005, p.31).

Além disso, eles expressam valores superiores de um sistema jurídico e que servem de base para a criação das normas de conduta, ou seja, toda regra deve ser criada por autoridade competente, estar coerente com os princípios constitucionais e mantendo a coerência do sistema. As normas dirigidas aos órgãos aplicadores do direito são utilizadas, se necessário, no processo de decisão, como ferramenta de apoio quando o caso é de difícil solução ( hard case). Um exemplo é a utilização do princípio da razoabilidade quando exige-se uma decisão equilibrada. Os autores Atienza e Manero 
afirmam que: "Obviamente, los principios están conectados con la realización de todas las funciones sociales desempeñadas por el derecho; y también con la realización de las funciones internas del derecho, las conectadas con los principios institucionales (2005, p.49)"'.

É preciso ainda diferenciar os princípios das diretrizes que integram o Direito. As últimas são normas que geram razões para a ação de tipo utilitário, ou seja, a execução de certo fim faz com que exista uma razão a favor daquilo que conduza ao fim. A razão não é excludente, pois podem existir outras razões contrárias e que tenham uma maior força. Porém, as razões que derivam de princípios são de correção e de última instância. Diante de uma razão para fazer uma determinada ação, o deixar de fazer somente estaria justificado mediante outra razão do mesmo tipo apoiada também em outro princípio. Em ambas as ações (operadas por princípios ou diretrizes) exigir-se-á ponderação, ou seja, analisar qual entre dois princípios prevalece em relação ao outro concorrente. Segundo Atienza e Manero:

Los principios son menos que las reglas. Por un lado, no presentan las ventajas de las reglas, pues no permiten ahorrar tiempo a la hora de decidir un curso de acción. Pues si una regla es aceptada y ella es aplicable al caso que nos ocupa, entonces se evita tener que entrar en un proceso de ponderación de razones en pro y en contra de una determinada decisión; la regla opera, por tanto, como un elemento que reduce la complejidad de los procesos de argumentación. [...]. Son también más que las reglas, y en otros dos sentidos. Por un lado, porque estar enunciados - o poder enunciarse - en términos más generales, entran también en juego en un mayor número de situaciones; esto es, del mismo modo que tienen un mayor poder explicativo que las reglas, tienen también un mayor alcance justificativo (2005, p.45).

A ponderação é necessária exatamente nos casos em que a solução está baseada em princípios e estes encontram-se em conflito, como ocorre na situação envolvendo fetos anencéfalos, entre outros. Conforme podemos perceber na passagem abaixo:

[...] los principios en sentido estricto no tratan de ordenar la concurrencia de intereses ni de promover unos u otros intereses sociales, sino de evitar que la persecución de cualquiera intereses pueda dañar a dichos valores. El dichos valores se consideran como razones categóricas frente 
a cualesquiera intereses no excluye, obviamente, la posibilidad de conflicto entre ellos. Al menos los ordenamientos jurídicos liberaldemocráticos recogen una pluralidad de valores cuya jerarquía interna no siempre se encuentra predeterminada por el ordenamiento mismo. De ahí la posibilidad de que se produzcan conflictos que sólo cabe resolver tras una ponderación de la que resulte cuál es el valor que tiene un mayor peso, dadas todas las circunstancias del caso (2005, p.41).

Assim, os princípios são metas eleitas por um Estado, através de acordos, discussões políticas, negociações, ideais de política, justiça, pacto, contrato, lutas de classes, entre outras motivações, e que se tornam as vigas mestras do edifício jurídico.

Segundo a tese de Atienza e Manero o conceito de "princípio" é usado em inúmeros contextos jurídicos e em diferentes situações concretas, pois eles exercem um papel essencial em todos os setores do Direito, em especial, nas situações em que as regras não oferecem uma solução adequada. Dessa maneira, formam uma "semelhança de família" complexa e unida por laços de parentesco (STRUCHINER, 2002, p.27) e (CARRIÓ, 1998, p.201). Para esclarecer essa afirmação utilizaremos alguns exemplos de Princípios do Ordenamento Jurídico brasileiro para demonstrar a vinculação com os múltiplos significados expostos acima por Carrió e que formam família de conceitos. O Princípio que estabelece a "erradicação da pobreza, marginalização e redução das desigualdades sociais" pode ser vinculado nos itens (II e IV); o princípio da "moralidade pública" (VI e VII); o princípio da "dignidade da humana" (I, III, IV e V).

Podemos ainda encontrar outra forma para descrever a natureza dos princípios a partir das palavras de Daniel Sarmento:

Os princípios representam as traves-mestras do sistema jurídico, irradiando seus efeitos sobre diferentes normas e servindo de balizamento para a interpretação e integração de todo setor do ordenamento em que radicam. Revestem-se de um grau de generalidade e de abstração superior ao das regras. Sendo, por conseqüência, menor a determinabilidade do seu raio de aplicação. Ademais, os princípios possuem um colorido axiológico mais acentuado do que as regras, desvelando mais nitidamente os valores jurídicos e políticos que condensam (2003, p.42).

Porém, segundo Canaris, os princípios não permitem a subsunção direta como ocorre com as regras jurídicas, ou seja, eles não possuem o que se chama 
de "fattispecie" (fato típico ou tipicidade, natureza descritiva de fato, individualização da conduta relevante) e não podem ser mecanicamente aplicados pela insuficiência do grau de concretização. Porém, tanto as regras quanto os princípios possuem certo grau de generalidade, mas com natureza distinta. A generalidade de regras é necessária para que a mesma possa incidir no maior número possível de fatos ou atos, ou seja, a regra possui característica geral, abrangente ao seu espaço, mas com limitação.

Em outras palavras, segundo Alchourrón e Bulygin (1971), normas são sentenças hipotéticas ou condicionais compostas por duas partes: o antecedente que estabelece uma descrição de casos genéricos (fato típico, tipicidade) (â), ou seja, compõe-se de enunciado descritivo de casos gerais. A segunda é o consequente da norma, composto por um enunciado prescritivo de sanção (Ô) e operadores deônticos (î) que determinam as consequências normativas do caso que se submete ao caso genérico (do antecedente). Tais afirmações podem ser ilustradas da seguinte forma: (Se â então ì Ô). Um exemplo retirado do Código Penal é o Art. 138: "Caluniar alguém, imputando-lhe falsamente fato definido como crime (parte antecedente), pena, detenção, de seis (6) meses a dois (2) anos, e multa" (consequente). O operador deôntico está implícito no consequente, ou seja, o infrator "deverá" ser detido pelo prazo descrito na norma, a saber, de seis meses a dois anos e multa. Assim, a função do operador do Direito é subsumir os casos individuais à regra geral, a fim de oferecer uma solução normativa. Mas essa tarefa nem sempre é tão simples e operacional como parece, pois nem todo caso é simples.

Em geral afirmamos que as normas jurídicas sempre são condicionais e que todas aquelas que parecem incondicionais (obrigatórias e proibidas) podem ser convertidas em hipotéticas. Porém, diante da descrição do fato típico e escolha do cidadão, ele estará assumindo as consequências de sua tomada de decisão. Exemplo: a cor vermelha de uma sinaleira prescreve ao condutor que pare diante do semáforo; se o mesmo decidir avançar está, potencialmente, sujeito a uma sanção pelo ato infracional. O condutor terá duas opções: parar ou avançar o sinal. Para Atienza e Manero (2005, p.31), "[...] las reglas son normas que exigen un cumplimiento pleno y, en esa medida, pueden siempre ser cumplidas o incumplidas. Si una regla es válida, entonces es obligatorio hacer precisamente lo que ordena, ni más ni menos".

Assim, regras são determinações (obrigações, proibições, autorizações) do tipo "tudo ou nada", ou seja, estabelecem claramente o 
que deve, o que pode ou não pode ser realizado. Nesta perspectiva entendemos que são procedimentos (ordens) que serão cumpridas na sua integralidade ou descumpridas. Se a regra é válida (criada por autoridade e coerente com os princípios constitucionais) então temos o dever de obedecêla, pois ela é detentora de legitimidade. Porém, o cidadão terá a capacidade de escolha diante dessa norma (segui-la ou não segui-la), mas assumirá os efeitos (físicos, psicológicos ou financeiros) da sua decisão. Elas diferem dos princípios, uma vez que esses são cumpridos em graus, pois são diretrizes ou normas programáticas que deverão ser realizadas de alguma forma e caberá ao poder público definir os meios para a efetivação, como é o caso da erradicação da pobreza, educação, saúde, entre outros. Já o exemplo de regra (tudo ou nada) pode ser a caracterização da maioridade penal no direito brasileiro a partir dos dezoito anos de idade. Os autores Atienza e Manero salientam ainda que:

La diferencia estriba en que los principios configuran el caso de forma abierta, mientras que las reglas lo hacen de forma cerrada. Con ello queremos decir que mientras que en las reglas las propiedades que conforman el caso constituyen un conjunto finito y cerrado, en los principios no puede formularse una lista cerrada de las mismas: no se trata sólo de que las propiedades que constituyen las condiciones de aplicación tengan una periferia mayor o menor de vaguedad, sino de que tales condiciones no se encuentran siquiera genéricamente determinadas. El tipo de ingerminación que aqueja a los principios es, pues, más radical que el de las reglas (aunque, desde luego, entre uno y otro tipo de indeterminación puede haber casos de penumbra) (2005, p.30 e 31).

Parece-nos que os princípios, por serem porosos (DIMOULIS, 2003, p.77) ou dotados de "textura aberta" (STRUCHINER, 2002) e dependerem de outras regras para sua concretização, podem ser realizados apenas parcialmente, pois mesmo que o Estado se esforce para alcançar a efetivação integral de todos eles é possível que num determinado caso ocorra a concorrência entre princípios e, ao final, um deles terá a prevalência sobre o outro. Logo, ao menos um dos princípios não será totalmente satisfeito.

Assim, encerramos a distinção entre esses dois conceitos jurídicos, mas faremos essa mesma comparação com os princípios e regras na moralidade. A seguir trataremos dos conflitos (incompatibilidades) no Direito e as medidas que são adotadas. 


\section{CONFLITO ENTRE REGRAS E CONFLITO ENTRE PRINCÍPIOS}

Em síntese, todo caso jurídico deve ser solucionado se possível, primeiramente, por uma regra válida e só depois recorre-se aos princípios; identificada uma incompatibilidade entre regras (em sentido estrito, ou seja, impossibilidade de cumprimento de duas normas com diretrizes opostas valendo para o mesmo caso) é preciso utilizar regra de exceção ou método para superação das antinomias; a incompatibilidade entre regras remete ao problema de validade ou de pertença ao Direito (Alexy, 2007, p.85) e a solução perpassa pela derrotabilidade de uma delas; as medidas tomadas nesse âmbito só têm aplicabilidade sobre as regras. Entretanto, se as regras são insuficientes ou incapazes de resolver um caso, então recorre-se aos princípios jurídicos; se o caso concreto possibilitar a aplicação de mais de um princípio com solução distinta, então haverá conflito (incompatibilidade em sentido amplo ou fraco, pois os princípios são válidos independentemente dessa colisão); é necessária uma análise a partir da ponderação, pois entre eles existe uma concorrência e não podemos falar em derrotabilidade de princípio; esse procedimento de ponderação é medida adotada exclusivamente para colisão de princípio e não está acessível às regras. A seguir faremos uma descrição detalhada dessa situação.

Princípios, ao contrário das regras, e por causa de sua generalidade, aplicam-se a uma infinidade de tipos de casos. A escolha dentre eles está associada ao "peso e importância" que cada princípio tem com respeito àquele caso. "Os princípios possuem uma dimensão que as regras não têm - a dimensão do peso ou importância. Quando os princípios se entrecruzam, aquele que vai resolver o conflito tem de levar em conta a força relativa de cada um [...]", Dworkin 2002, p.43). Para resolver situação conflitante entre princípios é necessário adotar um procedimento de "ponderação" (ALEXY, 2007, p.70 ss) entre eles (cabe ressaltar que não é método de solução normativo, mas uma medida adotada pelo magistrado nesse tipo de circunstância) e não uma escolha e aplicação de um dos princípios sobre o outro. Isso porque segundo Letízia Gianformaggio (apud, SARMENTO, 2003, p.47), “os princípios jamais são incompatíveis entre si: são sempre concorrentes". O conceito de incompatibilidade, nesse contexto, possui duplo significado: num sentido forte e fraco. A incompatibilidade do primeiro tipo está relacionada com o âmbito da validade das regras e ambas não podem 
valer ao mesmo tempo no sistema, ou seja, no caso de uma regra prevalecer sobre outra essa sempre prevalecerá sobre essa outra. Já o conflito existente entre princípios é num sentido mais fraco, pois todos eles são válidos no sistema. Dito de outra forma, eles não "são" incompatíveis entre si (em sentido forte), mas podem "estar" em conflito em um caso concreto e, em seguida, perfeitamente compatíveis novamente, ou seja, um deles pode prevalecer num caso específico e não em outro. A solução para esse tipo de situação é adotar a ponderação que é descrita por Alexy como "relação de precedência condicionada".

La solución de la colisión consiste más bien en que, teniendo en cuenta las circunstancias del caso, se establece entre los principios una relación de precedencia condicionada. La determinación de la relación de precedencia condicionada consiste en que, tomando en cuenta el caso, se indican las condiciones en las cuales un principio precede al otro. En otras condiciones, la pregunta acerca de cuál de los principios debe preceder, puede ser solucionada inversamente (2007, p.73).

Assim, a impossibilidade de realizar os princípios no caso concreto e as consequentes soluções distintas não geram uma inconsistência no ordenamento jurídico, pois o que existe é apenas uma oposição entre eles e o caso em questão (problema fático) solucionável por um procedimento de ponderação, mas princípios por si só não são incompatíveis no sistema jurídico (não há um problema interno). Vejamos o exemplo descrito por Sarmento:

$\mathrm{O}$ direito previsto pelo Art. $5^{\circ}$, IV, da Constituição, que, conquanto expresso em termos absolutos - é livre a manifestação do pensamento, sendo vedado o anonimato -, tem caráter de princípio, podendo ter a sua aplicação no caso concreto afastada após a ponderação com outros interesses constitucionais, como é o caso da admissão da proibição de manifestações de apologia ao crime, em razão da proteção da segurança pública (2003, p.48).

Ao contrário, o conflito de regras sobre o mesmo caso e no mesmo ordenamento gera uma inconsistência e é solucionável mediante a adoção de métodos do próprio conjunto de regras, a saber, cronologia, hierarquia e especialidade a fim de optar por uma delas e desconsiderar a outra. Segundo Alexy (2007, p.69) o conflito de regra é solucionado através do uso de regras 
de cláusula de exceção que determinam a validade de apenas uma em detrimento da outra ou pelo uso dos métodos da hierarquia, cronologia ou especialidade. Já no caso dos princípios a saída encontra-se no peso atribuído a cada um em relação ao caso concreto e jamais se discutirá o âmbito de validade dos mesmos. Nas palavras de Sarmento: "Inexiste hierarquia entre princípios constitucionais explícitos e implícitos. Estes podem concorrer com aqueles em casos concretos, impondo-se, nesta hipótese, o empreendimento de uma ponderação de interesses para a resolução satisfatória da controvérsia (2003, p.54)".

\section{PRINCÍPIOS E REGRAS NA MORAL}

Passemos à análise e classificação de regras e princípios no âmbito da moral apoiados num artigo de Marcus Singer intitulado "Moral rules and principles" e comparar com o sistema jurídico descrito acima. Nesse artigo o autor apresenta uma distinção entre esses conceitos e procura demonstrar como os princípios estão envolvidos na justificação e no estabelecimento das regras morais. Os princípios morais são considerados como regras invariáveis que servem para criar novas regras morais, mudar as antigas, oferecer soluções mais adequadas, método para preencher lacunas e resolver eventuais conflitos entre regras (antinomias). Essa caracterização aproxima-se ao âmbito jurídico em inúmeros pontos, que serão identificados ao longo do texto. Segundo William Whewell: "Who speaks of moral principles as the fundamental maxims or rules, the basis of other rules, and says that in order [...] to establish and apply moral rules, we must state the moral principles which are the foundation of such rules ( $a p u d$, SINGER, 1958, p.160)".

Mas toda discussão apresentada por Singer a respeito da classificação moral de princípios e regras em analogia ao sistema jurídico está apoiada na tese de Roscoe Pound. Para esse autor:

As regras ou leis, isto é, provisões definitivas e detalhadas para definitivos e detalhados estados de fato, são a base fundamental dos princípios de direito. Na maturidade do direito, aquelas são principalmente empregadas em situações onde não há uma excepcional necessidade de certeza, a fim de se manter a ordem econômica. Com o advento da escrita legal e da teoria jurídica, na transição da lei escrita para a equidade e o direito natural, um 
segundo elemento se desenvolveu e tornou-se um fator de controle na administração da justiça. Em lugar de regras detalhadas, determinando exatamente o que acontecerá em face de uma situação de fato precisamente detalhada, passa confiar-se em premissas gerais para o raciocínio dedutivo, judicial e jurídico. Esses princípios legais, como lhes chamamos, são utilizados para fornecer novas leis, interpretar antigas, medir o âmbito e aplicação de regras e normas e reconciliá-las quando conflitam ou se sobrepõem (1965, p.62).

Princípios não estabelecem as condições de "certo e errado", do que "deve ou não deve ser", não contêm "fato típico" e atribuições exclusivas das regras morais (SINGER, 1958 p.164). Todo princípio possui, pelo menos, uma regra que permite sua realização. Além disso, eles não permitem exceções, são invariantes e não entram em conflito entre si (SINGER, 1958, p.192), como ocorre em certas ocasiões no Direito. Entretanto, poderiam concorrer para uma solução mais adequada e distinta em um caso concreto e, nesse sentido, sugerimos a adoção da "ponderação" dentre eles, ou seja, análise do "peso" dos princípios que estão em concorrência (tese de Alexy) e relativamente ao fato. Dependendo da circunstância um deles se mostrará mais adequado que o outro (terá peso maior), mas em outra oportunidade poderá ocorrer uma inversão.

Nas palavras de Singer (1958, p.170): “A little reflection suffices to show that it is impossible for any of these principles to conflict, though they are all closely related, and this is a further important difference between moral rules and principles". O autor não descarta a hipótese da aplicação de dois princípios para um caso concreto com soluções distintas, mesmo assim eles não estão em conflito (contradição), mas em concorrência. Em outras palavras, os princípios estão em perfeita harmonia quando descolados da realidade, mas podem concorrer em determinados casos por oferecer soluções distintas. Além disso, se eles fossem realmente incompatíveis (sentido estrito) estaríamos diante de uma crise do sistema, o que exigiria a eliminação de um deles. A validade é condição inerente ao princípio e eles não são incompatíveis. Dessa maneira, se surgir incompatibilidade (em sentido forte) é resultado do conflito entre princípios de sistemas morais distintos e não no interior da própria teoria moral.

Logo, a fórmula da ponderação utilizada no direito para resolver os embates entre princípios poderia, por analogia, ser aplicada ao âmbito moral. 
Assim, quanto maior o grau de não satisfação ou afetação de um dos princípios maior será a importância da satisfação do outro. Para Alexy (2007) esse grau é dividido em três níveis, a saber, leve, médio ou intenso. Consideremos o exemplo envolvendo a necessidade de transfusão sanguínea de uma criança em conflito com a liberdade religiosa dos pais. O grau de afetação da vida e da saúde da criança é considerado de nível intenso em razão do risco de vida, enquanto a liberdade de culto dos pais terá um grau médio ou leve. Logo, esse procedimento permite avaliar e obter uma reposta ponderada a partir da análise do caso concreto.

Por outro lado, a escolha pode ser guiada por uma análise de prevalência de valores, ou seja, certos princípios podem ter peso abstrato maior em relação ao outro no caso concreto. Segundo Jopeh Raz (2004) a vida, por exemplo, é pressuposto para garantir os demais direitos, pois sem ela é impossível a concretização de outras garantias fundamentais. Novamente a ponderação permite identificar a primazia de um sobre os outros. Marcus Singer apresenta alguns exemplos de princípios morais. São eles:

Let us now consider some examples of moral principles: a) Generalization argument; b) Generalization principle; c) Principle of consequences (if the consequences of A's doing $x$ would be undesirable, then A ought not to do $\mathrm{x}$ ); d) It is always wrong to cause unnecessary suffering; e) Principle of justification (Any violation of a moral rule must be justified (1958, p.162 e 170).

Vamos esclarecer a diferença entre os dois primeiros princípios citados por ele, a saber, "argumento de generalização" e "princípio de generalização". O primeiro é mais básico e não exige conhecimento prévio acerca do direito de fazer ou não fazer, pois com ele é possível calcular quando não se é detentor de um direito. Se a consequência de todos agirem de certo modo for desastrosa, então ninguém tem o direito de agir daquela maneira. $\mathrm{O}$ princípio de generalização propõe que aquilo que é direito para uma pessoa também é para qualquer pessoa similar em circunstâncias similares. Ou, aquilo que não é de direito para uma pessoa também não é de direito para qualquer pessoa similar em circunstâncias similares. Esse princípio exige que se tenha um conhecimento prévio de alguém que seja detentor de um direito ou de alguém que não seja detentor de certo direito. 
Passamos, nesse momento, a análise das regras morais. Elas são divididas em: a) regras morais fundamentais (contra a mentira, matar ou furtar); b) regras neutras (como as regras de trânsito); c) regras locais (costumes e tradições peculiares a determinados grupos ou comunidades por exemplo, pagar taxas) (SINGER, 1958, p.176). Nossa análise se restringe apenas às primeiras.

Para o autor (1958, p.193): "There is nothing that can correctly be said to be right or wrong; it is only a question of what is called right or wrong, and by what group it is so called". Além disso, as regras que estabelecem o que é certo e errado permitem exceções, pois dependendo da circunstância ela pode ser derrotada por entrar em conflito ou por existir uma justificativa para não segui-la. Por exemplo, na maioria dos sistemas morais o ato de mentir ou trair confiança é reprovado, porém pode existir situação em que isso represente uma questão de sobrevivência.

Essa tese de Singer se aproxima da crítica de Richard Hare ao formalismo kantiano da universalidade irrestrita dos deveres morais, isto é, da sua incondicionalidade, sem exceção. Para Hare os deveres morais possuem uma validade incondicional e universal apenas de maneira prima facie, ou seja, devem ser seguidos na maioria das vezes, mas em circunstâncias muito específicas podem dar lugar a outro dever moral prima facie. Essa exceção deve estar justificada (com razões) por uma escolha não arbitrária. O princípio tradicionalmente aceito de "não matar", por exemplo, é válido prima facie na maioria das vezes, mas pode deixar de valer para o caso de aborto de fetos anencéfalos.

Assim, para Singer, as regras morais não possuem caráter absoluto (como é o caso dos princípios, SINGER, p.192) do que deve ou não ser feito e não existe o certo ou errado enquanto essência, mas aquilo que qualificamos como certo ou errado. Além disso, elas variam de sociedade para sociedade e permitem exceções em determinados casos. Nessa perspectiva, trata-se de um critério de avaliação oriundo do paradigma em que o sujeito está inserido (formado pela cultura, costume, religião, moral geral). Logo, um ato não é, em si, moral ou imoral, mas uma qualidade que atribuímos.

Outra diferença entre regra jurídica e moral refere-se ao significado de obrigação, ou seja, para o direito afirmar que uma ação é correta e errada significa que ela deve ou não ser realizada (ordem prescritiva, 
determinação). Já a regra moral, segundo ele, depende da crença do agente, tem caráter de orientação e exige respeitabilidade geral e não uma obrigatoriedade em sentido forte. Vejamos:

Now a moral rule can prohibit, require, or permit a certain kind of action. If a certain kind of action is prohibited by a rule, then actions of that kind are generally wrong; if it is required, then it is generally wrong not do an act of that kind; and, if it is permitted, then actions of that kind are generally not wrong (SINGER, 1958, p.164)

Ademais, as ações morais são geralmente certas ou erradas, isto é, contrariar uma regra necessariamente exigirá razões que justifiquem tal atitude. Argumenta ainda (1958, p. 165) que ações morais sempre certas ou erradas são aquelas em que tais qualificativos ocorrem em todas as circunstâncias, condições e sociedades (o que parece difícil acontecer). Em outras palavras, o qualificativo vai depender da justificativa para a realização ou não do ato. Tomamos um exemplo usual: mentir é errado. É preciso justificar o porquê essa ação é reprovada pelo sistema moral; expor os motivos pelos quais o grupo considera inadequado. As vezes não é suficiente afirmar que as razões estão apoiadas na reprovação da maioria. É preciso buscar razões através do argumento da generalização (princípio moral) como "meio" (o argumento da generalização é usado como procedimento, pois é mais fácil, automático e prático na solução do problema) (SINGER, 1958, p.192). Isso significa que se alguém tem o direito de mentir, então todos tem o mesmo direito: "se alguém pode todos podem" (1958, p.186).

Em síntese, (SINGER, 1958, p.169 e 192), a distinção entre princípios e regras morais está em que os primeiros não são derrotáveis e não permitem exceções, enquanto as regras morais são derrotáveis (em confronto umas com as outras) e permitem exceções (quando houver justificativa para não segui-las).

\section{CONSIDERAÇÕES FINAIS}

Chegamos ao final do trabalho antecipando algumas afirmações que não foram diretamente exploradas, mas que são resultado da análise sobre o tema e serão tratadas em outra oportunidade. Nessa tarefa de comparação 
do direito com a moral identificamos alguns pontos de contato e algumas diferenças.

As Aproximações: 1. O sistema, moral ou jurídico, formado apenas por regras de conduta não dá conta da complexidade da deliberação atual; 2. Ambos os sistemas são formados por princípios e regras; 3. Os princípios têm a função de preencher espaços vazios, base para a modificação, criação e alteração de regras; 4. Não há hierarquia entre princípios; 5. Jamais estão em conflito ou em contradição em sentido forte (não são incompatíveis entre si), mas podem concorrer em determinados casos concretos; 6. Caso isso ocorra no direito utiliza-se a ponderação dos valores em conflito mensurando o peso de cada um deles com o caso concreto (um deles é derrotado nessa circunstância e ambos permanecem válidos). Esse mesmo procedimento pode ser adotado, por analogia, em uma provável concorrência de princípios morais; 7. Já as regras são a efetivação desses princípios; 8. Elas possuem um caráter de "tudo ou nada", ou seja, realizáveis ou não; 9. Podem entrar em conflito entre si e, nesse caso, uma delas é derrotável com relação a outra e não valem ao mesmo tempo no mesmo sistema. 10. A solução da incompatibilidade ocorre por apelo a outra regra que defina a validade de uma delas ou que permita a exceção da regra.

As Diferenças: 1. A correlação "mundo dos fatos e mundo das regras" (para cada caso deve existir uma regra para solução) são distintos no direito e na moral. O mundo dos fatos do direito é constantemente modificado, ampliado e, com frequência, não proporciona solução adequada para todos os casos a partir de regras, em razão do surgimento ou de lacuna ou antinomia e, portanto, apela-se aos princípios (o sistema deve ser mais dinâmico). Já na moral esse processo é mais lento, os casos são mais estáveis e há uma exigência menor dos princípios morais para a solução de casos que fogem às regras. 2. A solução para esses problemas, no direito, está presente em outra regra (está codificada). Já na moral essa medida é informal, pois não está codificada. A deliberação jurídica feita a partir de princípio em razão da insuficiência da regra pode ser utilizada, por analogia, na deliberação moral. 3. A solução de um eventual conflito moral de regra é solucionável pelo próprio agente moral a partir do pressuposto teórico adotado e não por procedimento formal da moralidade. 4. O conflito de princípio moral, segundo Singer, não pode ocorrer dentro do sistema e, portanto, não são derrotáveis. Diferentemente no Direito pode ocorrer uma concorrência (incompatibilidade em sentido fraco) e um deles será derrotado 
no caso específico. 5. Acreditamos que se houver incompatibilidade de princípios morais é resultado de teorias e valores distintos aplicados ao caso concreto e não no interior de uma mesma teoria moral; 6. Logo, pode acontecer que diante de um conflito agentes morais tomem medidas distintas baseadas em suas teorias de base. Já no Direito a divergência (gerada pelo conflito ou por teorias distintas) deve ser solucionada com base no próprio sistema jurídico único.

\section{REFERÊNCIAS}

ALEXY, Robert. Teoría de los derechos fundamentales. Madrid: Centro de Estudios Políticos y constitucionales, 2007

ALCHOURRÓN, Carlos; BULYGIN, Eugenio. Normative systems. New Cork: Springer Verlag, 1971.

ATIENZA, Manuel. As razões do direito. São Paulo: Landy, 2002.

. Sobre lo razonable en el derecho. In: Revista Española de Derecho Constitucional. N. 27, 1989, p.93-110.

; MANERO, Juan. Las piezas del derecho. Barcelona: Ariel, 2005.

ÁVILA, Humberto. Teoria dos princípios: da definição à aplicação dos princípios jurídicos. São Paulo: Malheiros, 2007.

BOBBIO. Norberto. Teoria do ordenamento jurídico. Brasília: UnB, 1999.

BRINK, David. Moral conflict and its structure. The Philosophical Review. V.103, n.2, 1994, p.215-247.

CARRIÓ. Genaro. Notas sobre derecho y lenguaje. Buenos Aires: Abeledo Perrot, 1998. 
DIMOULIS, Dimitri. Manual de introdução ao estudo do direito. São Paulo: Editora RT, 2003.

DWORKIN, Ronald. Levando os direitos a sério. São Paulo: Martins Fontes, 2002.

GRAU, Eros Roberto. Ensaio e discurso sobre a interpretação e aplicação do direito. São Paulo: Malheiros, 2006

GUEST. Stephen. Ronald Dworkin. Rio de Janeiro: Elsevier, 2010.

HART, Herbert L. A. Direito, liberdade e moralidade. Porto Alegre: Sérgio Fabris Editor, 1987.

2001

. O conceito de direito. Lisboa: Fundação Calouste Gulbenkian,

LARIGUET, Guillermo. Conflictos trágicos genuinos, ponderación y límites de la racionalidad jurídica. In: Doxa - n.24, abril de 2006, p.94-113.

MARCUS, Ruth. Moral dilemmas and consistency. The Journal of Philosophy. vol LXXVII, n.3, 1980.

NAVARRO, Pablo. Sistema jurídico, casos difíciles y conocimiento del derecho. In: Doxa, n.14, 1993, p.243-268.

POUND, Roscoe. Introdução a filosofia do direito. Rio de Janeiro: Zahar Editores, 1965

PULIDO, Carlos B. Estructura y límites de la ponderación. In: Doxa, n.26, 2003, p.225-238

RAZ, Joseph. Valor, respeito e apego. São Paulo: Martins Fontes, 2004.

SARMENTO, Daniel. Ponderação de interesses na constituição

federal. Rio de Janeiro: Lumen Juris, 2003 
SINGER, Marcus. Moral rules and principles. In: Essays in moral philosophy. University of Washington Press, 1958, p.160-197.

STATMAN, Daniel. The debate over the so-called reality of moral dilemmas. Philosophical Papers, vol. XIX, 1990, p.191-211.

. A new argument for genuine moral dilemmas? The journal of value inquiry. Vol., 1992, p.565-575.

. Hard cases and moral dilemmas. Law and Philosophy, vol. XV, 1996, p.117-148.

STRUCHINER, Noel. Direito e linguagem: uma análise da textura aberta da linguagem e sua aplicação no direito. Rio de Janeiro:

Renovar, 2002.

Submetido em: 13/05/2013

Aprovado em: 08/07/2013

Como citar: GHIDOLIN, Clodoveo. Classificação em princípios e regras na deliberação jurídica e moral. Scientia Iuris, Londrina, v.17, n.1, p.179-198, jul.2013. DOI: 10.5433/2178-8189.2013v17n1p179. 